\title{
La forma como ley natural en Francis Bacon*
}

Fecha de entrega: 2 de junio de 2017

Fecha de evaluación: 26 de julio de 2017

Fecha de aprobación: 11 de agosto de 2017

\author{
Damián Pachón Soto**
}

\section{Resumen}

El trabajo de investigación busca esclarecer la Forma baconiana como "ley natural". Se sostiene que los otros sentidos del concepto de Forma en Bacon, tales como diferencia verdadera, fuente de emanación o naturaleza naturante, forman parte de su eclecticismo, pero, en estricto sentido, esas expresiones no dicen nada en torno a las leyes de las naturalezas simples o de los fenómenos físicos. En contraste, la Forma como ley no solo permite comprender mejor la peculiar lectura de Bacon sobre la legalidad natural, sino que posibilita establecer nexos con la parte operativa. En la investigación también se escudriñan las relaciones de la ley natural baconiana con la teología y la ley jurídica.

Palabras clave: Bacon, Forma, ley natural, movimiento, ciencia moderna, teología voluntarista, operatividad.

* Artículo de investigación. DOI: http://dx.doi.org/10.15332/s0120-8462.2017.0117.05

* Doctor en Filosofía y magister en Filosofía Latinoamericana. Profesor e investigador en temas de poscolonialidad y pensamiento colombiano. Ha publicado varios libros y artículos en revistas especializadas y diarios nacionales e internacionales. damianpachon@usantotomas.edu.co. 


\section{The method as natural law in Francis Bacon}

\section{Damián Pachón Soto}

\section{Abstract}

The research work seeks to clarify the Baconian Method as "natural law". It is argued that the other meaning of the Bacon Method concept, such as true difference, source of emanation or nature naturing, are part of its eclecticism, but, in a strict sense, these expressions say nothing about the laws of simple natures or physical phenomena. In contrast, the Method as a law not only allows us to better understand Bacon's peculiar reading about natural legality, but it also makes it possible to establish associations with the operative part. The research also examines the relationship between Bacon's natural law with theology and legal law.

Keywords: Bacon, Method, natural law, movement, modern science, theological voluntarism, operability.

\section{A forma como lei natural em Francis Bacon}

\section{Damián Pachón Soto}

\section{Resumo}

O trabalho de pesquisa busca esclarecer a Forma baconiana como "lei natural". Sustenta-se que os outros sentidos do conceito de Forma em Bacon, tais como diferença verdadeira, fonte de emanação ou natureza naturante, formam parte de seu ecletismo, mas, em sentido estrito, essas 
expressões não dizem nada sobre as leis das naturezas simples ou dos fenômenos físicos. Em contraste, a Forma como lei não só permite compreender melhor a peculiar leitura do Bacon sobre a legalidade natural, senão que possibilita estabelecer nexos com a parte operativa. Na pesquisa também se perscutram as relações da lei natural baconiana com a teologia e a lei jurídica.

Palavras-chave: Bacon, Forma, lei natural, movimento, ciência moderna, teologia voluntarista, operatividade.

\section{Introducción ${ }^{1}$}

En los estudios realizados hasta hoy, el problema de la Forma baconiana sigue siendo álgido. A pesar de la renovación que surtieron los estudios a partir de las obras The Philosophy of F. Bacon de F. Anderson de 1948, Francis Bacon: filósofo de la revolución industrial de Benjamin Farrington de 1951, el fundamental Francis Bacon: de la magia a la ciencia de Paolo Rossi de 1956, el libro Francis Bacon's Philosophy of Science de Peter Urbach de 1987, el estudio de Antonio Pérez-Ramos titulado Francis Bacon's Idea of Science and the Maker's Knowledge Tradition de 1988; Entre el atomismo y la alquimia. La teoría de la materia de Francis Bacon de Silvia Manzo de 2006, o la tesis Francis Bacon's Science of Magic de Sophie Victoria Weeks de 2007, para mencionar algunos entre los más antiguos y más recientes, el tema de las Formas ha sido calificado de oscuro y confuso, cuando no abandonado injustificadamente. Veamos someramente los casos de Ellis, Farrington, Rossi y Pérez-Ramos, para ilustrar mejor lo afirmado.

R.L. Ellis, uno de los editores que realizó la edición aún canónica de las obras de Bacon, junto con Speeding y Heath, sostuvo que "me siento muy inclinado a creer que la doctrina de las Formas es, en algún modo, una parte extraña del sistema de Bacon", en especial, por el uso ambiguo del término, perteneciente más a su metafísica

1 En adelante, la obra de Bacon se cita de acuerdo con las siguientes siglas: AS = El avance del saber; DGI = Descripción del globo intelectual; DSS = Delineatio o Descripción y sumario de la segunda parte de la Instauratio; $\mathrm{NA}=$ La Nueva Atlántida; $\mathrm{NO}=$ Novum Organum; $\mathrm{SDA}=$ La sabiduría de los antiguos y W $=$ The Works of Francis Bacon (J. Speeding, R. Leslie Ellis y D. Denon Heath, Eds.), 1857-1874. En la lista de referencias aparecen los datos bibliográficos completos. 
que a su filosofía natural ${ }^{2}$. Más aún, Ellis estipuló que "su peculiar método puede ser establecido independiente de esta doctrina, y él mismo lo ha establecido así en su tratado temprano llamado Valerious Terminus" (Ellis, W., I, p. 71). Esto quiere decir simplemente que uno de los editores canónicos de su obra tachó de "extraño al sistema" el concepto mismo. Sin embargo, la apreciación de Ellis no se puede aceptar por la sencilla razón de que Valerius Terminus es un escrito de 1603, y Bacon aludió de nuevo a la Forma en 1605 en The Advancement of Learning e intentó desarrollarlo sistemáticamente, junto con la inducción, en la segunda parte del Novum Organum, así como en la reedición de El avance del saber en 1623 (en adelante, De Dignitate) donde alude a las Formas como sinónimo de ley (W., IX, p. 30).

El concepto de Forma vuelve a calificarse de oscuro en el libro referenciado de Farrington: "Lo que Bacon quería decir con Formas, o la verdadera diferencia específica, o la naturaleza-engendradora de la naturaleza, o la fuente de emanación, no ha resultado tan fácil de comprender; ni tampoco es razonable esperar que lo fuera" (Farrington, 1971, p. 124).

Un punto fundamental de inflexión lo encontramos sugerido en el libro citado de Paolo Rossi. En el Prefacio a la segunda edición de 1974, Rossi realiza una importante confesión: "Por lo que respecta a la lógica o al método hoy trataría de [...] subrayar más el vínculo entre la formulación del método y los intereses químico-alquimistas de Bacon, o si se prefiere la relación existente entre la teoría de la inducción y la llamada doctrina de las Formas" (Rossi, 1990, p. 11).

Pero este nuevo interés se debe a que, en la edición de 1956, si bien Rossi alude varias veces al problema de la Forma, en el capítulo 6 al tratar de "La tradición retórica y el método de la ciencia", el pensador italiano dice: "Lo que ahora interesa no es tanto una discusión de la compleja y confusa teoría baconiana de las formas, cuanto un nuevo examen de aquella máquina intelectual” (Rossi, 1990, p. 338). Lo que Rossi plantea claramente en 1974 es la necesidad de ahondar en esa "compleja y confusa teoría".

Por otro lado, el estudio de Antonio Pérez-Ramos liga la Forma, la obra y la inducción con la tradición “Maker's Knowledge” o “el conocimiento del creador”, artífice, o fabricante, es decir, la relación saber-hacer, donde "saber algo significaría hacer o

2 Para Bacon, la ciencia natural está constituida por la física y la metafísica. La primera estudia las causas eficiente y material; la segunda, las causas formales y finales. La causa Formal es asimilada a Forma y las causas finales son útiles para el estudio de las acciones humanas, mas no para la ciencia natural. 
poder hacer algo" (1988, p. 49). Pérez-Ramos ha hecho énfasis en que el concepto de Forma hace parte del "núcleo más técnico" - así como la inducción- de la obra de Bacon, sin embargo, no ha tenido el mismo reconocimiento que el método inductivo y fue "despedido como una herramienta totalmente inútil en la construcción de la ciencia moderna” (1996, p. 99). Si bien el filósofo español intenta esclarecerlo, rastreando sus antecedentes en el medioevo, ocupándose de la forma sustancial, y explorando sus presupuestos ontológicos, etc., su intento no es del todo satisfactorio pues concluye, entre otras cosas, que la Forma es una receta (1996, p. 109; 1988, p. 131), con la cual — se da la impresión - es posible pasar directamente de la ley a la operación, a las obras.

Hay que agregar que si bien el concepto ha sido abordado por otros intérpretes como Jardine (1974), Peter Urbach (1987), Zagorin (1999) y Graukoguer (2001), entre otros, el punto de llegada sigue siendo el mismo ${ }^{3}$. El concepto ha sido calificado de "rareza histórica" como dice Fletcher (2005, p. 58), y tal vez por eso en la historiografía "la Forma baconiana no tuvo descendientes directos" (Pérez-Ramos, 1996, p. 116).

Pues bien, mi objetivo en la presente investigación es retomar el concepto en la obra baconiana, defendiendo que la Forma se puede esclarecer mínimamente si se asume como "ley natural". De ahí que otros sentidos como "diferencia verdadera", "fuente de emanación o "natura naturans" (NO., II, 1), se pueden descartar si se trata de comprender: 1) en qué consiste la ley de las naturalezas simples ${ }^{4}$ o cualidades (frío, calor, densidad, raridad, ductibilidad, color, etc.) o los fenómenos físicos, y 2) si se trata de pasar a la parte operativa, correlato necesario de la parte teórica o metafísi$\mathrm{ca}^{5}$. Esta apuesta por la Forma como ley natural implica establecer relaciones con la teología y con la ley jurídica.

3 Solo Sophie Victoria Weeks (2007), acudiendo al atomismo, sostiene que el sistema de Bacon es coherente y que puede darse una explicación satisfactoria de las Formas. Sin embargo, su lectura pasa por alto que Bacon en 1620 abandona el átomo y el vacio, asi como la inmutabilidad de la materia por considerarlas "doctrinas falsas". En contraste, Bacon propone una teoría de la materia flexible y plegable que permite prescindir del vacío (NO., II, 48).

4 Estas naturalezas simples o cualidades son lo común a toda la naturaleza y son, a la vez, el objeto de estudio de la ciencia natural (W., VIII, p. 498; No., I, 121 y No., II, 1). Estas cualidades es lo que Bacon Ilama "alfabeto de la naturaleza", las cuales son limitadas, si bien Peter Urbach piensa otra alternativa (1987, pp. 22 y 70). El objetivo de la ciencia es encontrar la ley de esa configuración, así como la ley de los actos y apetitos (movimiento) de la materia.

5 Para Bacon, la metafísica tiene una parte teórica que es la Forma y, correlativamente, una parte operativa que es la magia natural o ciencia activa (W., VIII, p. 480). 
En el presente texto me centraré en estos aspectos, tratando de arribar al esclarecimiento de la Forma como ley natural, y rozando medianamente la parte operativa. Para desarrollar lo propuesto, el texto se divide en cuatro partes. En la primera, se expone el problema de la Forma y los distintos sentidos que tiene en la obra baconiana; en la segunda, se aborda la forma como ley natural. En un tercer momento, se exploran las posibles relaciones entre la ley jurídica y la ley natural; $y$, finalmente, se termina indagando sobre la forma y el problema del movimiento. Se termina con unas cortas conclusiones.

\section{Los sentidos de la Forma en Bacon}

Los párrafos origen de la oscuridad, la confusión y las disputas en torno al concepto de Forma en Bacon son, principalmente, dos. El primero:

La tarea y el propósito de la ciencia humana consiste en descubrir la Forma de una naturaleza dada, es decir, la diferencia verdadera o natura naturante o fuente de emanación, pues de los vocablos de que disponemos estos son los que más se aproximan a designar aquello de que hablamos. (NO, II, 1)

El segundo, "[... la Forma del calor o la Forma de la luz y la ley del calor y la ley de la luz son la misma cosa” (NO, II, 17).

Pues bien, en estos dos textos encontramos que la Forma se equipara con las siguientes cuatro expresiones: 1 ) diferencia verdadera, 2) natura naturante, 3 ) fuente de emanación y, 4) ley. Esto es lo que he llamado la "semántica de la Forma". Mi apuesta consiste en mostrar cómo el sentido de ley es el prevaleciente, pues los otros enfatizan aspectos diversos que distraen en torno a la apuesta baconiana de interpretar la naturaleza para "efectuar todas las cosas posibles" (W., V, p. 398). Centrémonos brevemente en los tres primeros sentidos para asir después la Forma como ley natural.

Sobre el sentido 1 dice Robert Leslie Ellis que diferencia verdadera se refiere a "la teoría de la definición por género y diferencia. La diferencia es lo que da a la cosa definida su carácter específico" (W., I, p. 74). Este es un eco aristotélico presente en Bacon, muy claro en su ejemplo de la naturaleza del calor definida como: 
El calor es un movimiento expansivo, contenido y que se desarrolla según las partes menores. La noción de expansión se precisa en los siguientes términos: expandiéndose en todas las direcciones, se inclina, sin embargo, un poco hacia arriba. Por su parte, el desarrollo según sus partes se precisa así: no es lento, sino vivaz e impetuoso. (NO, II, 20)

Aquí la atención de Bacon se centra en el calor, una de esas naturalezas simples que experimentamos en la naturaleza. Lo que encontramos es un intento, una anticipación o primera vendimia de la definición de calor, es decir, su Forma. Bacon dice en el mismo aforismo que el movimiento es como el género y, desde luego, el calor sería la especie. Este movimiento está limitado por las siguientes diferencias verdaderas: es expansivo, y siendo expansivo tiende hacia la circunferencia, en sus partículas más pequeñas, es un movimiento contenido, repelido y rechazado hacia atrás, de manera que adquiere un movimiento alternativo y constante de temblor, agitación, esfuerzo, "de ahí se origina ese furor del fuego y del calor". Por su parte, el movimiento de penetración y estimulación debe ser “algo rápido”. En este sentido, lo expansivo, lo contenido, etc., son la diferencia específica, lo que diferencia al calor como especie, de cualquier otra especie de movimiento. Estas características son lo que él llama "diferencia verdadera".

Hay que aclarar aquí que Bacon no está tratando con entes individuales o "sustancias primeras" y su respectiva inclusión ascendente en especies y géneros, sino con las Formas que atraviesan la totalidad de la naturaleza. Esto así porque, para el Canciller, el intento de hallar la Forma de una sustancia individual, como el cedro o el león, es un empeño vano. De ahí que su concepto de Forma no equivale a esencia, especie, principio interno del movimiento o causa de las cualidades o atributos de la cosa, tal como en la tradición aristotélica o medieval. Por eso afirma: "no se debe confundir las Formas de que hablamos [...] con aquéllas de que ha tratado hasta ahora la contemplación y las especulaciones" (NO, II, 17).

Sobre el sentido 2, la Forma entendida como natura naturans, es preciso decir: "Siempre es antitética a natura naturata, y el pasaje que consideramos nos sirve adecuadamente para expresar la relación que guarda la forma con respecto a la naturaleza fenoménica que resulta de aquella" (Ellis, W., I, pp. 74-75). Es decir, Bacon usa una expresión común ya en la Edad Media y que se populariza con Spinoza en el siglo XVII (Del Canto, 2010, pp. 171-172). En este caso, las naturalezas simples tienen primacía 
ontológica y conforman las demás cosas de la naturaleza, esto es, los particulares, los individuos o los fenómenos. Por ejemplo, las naturalezas simples (o configuraciones materiales) como la ductibilidad, la amarillez, la fluidez, etc., constituyen el oro. Esto quiere decir que las Formas, que Bacon utiliza a veces como sinónimo de naturaleza simple o dada (Dickie, 1923, pp. 428-437), son naturantes dando origen a la naturaleza fenoménica tal como la experimentamos con los sentidos.

Sobre el sentido 3, la Forma como fuente de emanación, es preciso decir que el sentido se explica acudiendo al neoplatonismo presente en la época de Bacon. Ese neoplatonismo tomó fuerza con la obra de Marsilio Ficino, quien no solo establecía en su Prisca Theologia una continuidad entre Zoroastro, Hermes, Pitágoras, Platón y Plotino, en quienes estaba la verdad y donde esta coincidía con el cristianismo, sino que pensaba que el aristotelismo consideraba la religión como "cuento de viejas", y eliminaba la inmortalidad del alma y la providencia divina (Kristeller, 2005, pp. 57-76; Granada, 2000, p. 132). Ficino influyó notoriamente en autores como Cornelious Agripa y, posteriormente, en contemporáneos de Bacon como Jhon Dee. Este último autor, y el mismo Bacon, ha sido asociado a los rosacruces y a la promoción del progreso científico (Yates, 2001, pp. 132 y 290).

El eclecticismo neoplatónico de Bacon es claro cuando afirma que "todas las cosas ascienden por una escala hasta la unidad" (W., VIII, p. 507; W., VI, p. 221). Esa unidad es el Uno neoplatónico del cual emana o se autodespliega todo lo demás, incluyendo las Formas y los individuos mismos que vemos en la naturaleza. Todo este engranaje remite a la causa primera, que es Dios. Por eso, la naturaleza misma (ley suma o ley suprema de la naturaleza) es La Gran Forma (NO., II, 52), de donde se derivan, de acuerdo con De Augmentis de 1623, las naturalezas simples o "Formas de primera clase" (W., VIII, pp. 507-508). De estas, a su vez, emanan las "Formas compuestas" o particulares.

Por esta razón no se puede estar de acuerdo con Robert Leslie Ellis cuando dice: "la frase fons emanationis no parece requerir ninguna explicación. Pertenece a la especie de lenguaje filosófico que intenta, con mayor o menor éxito, dar claridad de concepción por medio de metáforas" (W., I, p. 75). Por lo demás, como se explicó en la Introducción, Ellis considera que el método de Bacon puede entenderse perfectamente sin este concepto. 


\section{La Forma como ley natural}

Los tres sentidos anteriores no contribuyen al esclarecimiento de la Forma en el sentido de ley. Pueden tener validez para ciertos públicos a los cuales se dirigía, por ejemplo, para los neoplatónicos muestran el eclecticismo renacentista de Bacon, llevando al Canciller a asumir parte del lenguaje aristotélico y neoplatónico. Nada se dice sobre la ley como regularidad de los fenómenos físicos, su papel explicativo o predictivo. Por eso es necesario arribar a lo que Bacon llama "ley perpetua y uniforme" (W., VI, p. 221). Este tema lleva al escabroso y debatido tópico del surgimiento del concepto de ley natural en la ciencia moderna ${ }^{6}$. Al respecto ha habido un gran debate entre los especialistas por determinar la influencia de aspectos políticos, teológicos, éticos y jurídicos, en la formación de este concepto fundamental. El tema de la ley natural toma importancia para los historiadores de la ciencia a partir de los años del siglo pasado. En este sentido, fue Edgar Zilsel quien atribuyó el origen de la ley natural a factores externos, específicamente al capitalismo moderno ${ }^{7}$. Si bien desde los judíos, el Dios legislador gobierna el mundo con leyes y esa ley también se convierte en canon de la moralidad, lo que él llama "la metáfora de la ley", el concepto moderno de ley natural nace en el siglo XVII. Esta concepción sociológica apunta a que fueron las transformaciones que se dieron en la modernidad capitalista las que desembocaron en el concepto. Para Zilsel, los cambios materiales fueron fundamentales, así como el nacimiento de la monarquía absolutista, la necesidad de una legislación racional y el papel de las artes mecánicas. En todos estos casos, la legalidad es necesaria y, especialmente, la legalidad natural que ofrece un dominio del mundo y se compromete con las grandes transformaciones económicas. Dice Zilsel:

esencial a la ciencia moderna es la idea de que los científicos deben cooperar para producir el progreso de la civilización. Ni las disputas escolásticas ni literarias (o letradas), ni la ambición de gloria, son científicas. La idea de Bacon es sustancialmente nueva y no ocurre ni en la Antigüedad, ni en el Renacimiento. (2000, p. 944)

6 Hoy, después de décadas de debate, existe un consenso según el cual el concepto de ley natural no puede entenderse sin acudir a aspectos sociales, teológicos, jurídicos, éticos y semánticos. Véase González, A. M. (Eds.) (2008). Contemporary Perspectives of Natural Law. Natural Law as a limiting Concept, Routledge.

7 Pérez Ramos (1988, p. 122) ubica en este autor el nacimiento de las modernas disputas en torno al concepto de "ley natural". 
El problema de la lectura de Zilsel es que termina siendo secular, obviando los otros debates en torno al surgimiento del concepto y, por lo demás, modernizando demasiado la posición de Bacon.

Otras lecturas más aceptadas sobre el origen del concepto involucran perspectivas inmanentistas y otras trascendentes. En el primer caso, se acude al mundo griego para explicar cómo el cosmos mismo obedece a un logos, y es regido por él, tal como en el caso de los estoicos y el logos spermatikos ("semillas del logos"), donde las partes de la naturaleza guardan un orden y una conexión entre sí. En versiones trascendentes, el aspecto teológico recobra una especial importancia porque se acude a Dios como el creador e introductor de las leyes del mundo. En este caso, desde afuera, el mundo es creado y reglado. Aquí las discusiones han puesto especial atención a Tomás de Aquino y sus conceptos de ley divina y ley natural, aspecto que poco tenía que ver con el mundo práctico y los cambios operados en él, según Zilsel. Con todo, lo importante es la relectura de este problema desde la perspectiva del siglo XVII (Manzo, 2015). Aquí las discusiones en torno a la teología voluntarista e intelectualista, ambas de origen medieval, es importante. Dentro de la primera se ha ubicado a Scoto y a Ockham y, después, al propio Newton y Boyle; mientras que Tomás de Aquino sería un fiel representante de la segunda, donde también se ha incluido, no sin debate, a Descartes $^{8}$. En este sentido, es interesante el artículo del profesor de la Universidad de Edimburgo Jhon Henry. En un paper titulado "Voluntarist theology at the origins of Modern Science: a response to Peter Harrison", Henry defiende, contra Harrison, que el voluntarismo fue importante para el nacimiento de la ciencia moderna y para algunos de sus pensadores (2009, pp. 79-113) ${ }^{9}$. El debate entre ambas concepciones consiste en lo siguiente: para el intelectualismo, Dios crea el mundo de manera racional, con un orden y con una determinada lógica. Esto garantiza el orden de las cosas

8 Al respecto, dice Silvia Manzo: 'Según Descartes, Dios elige con su voluntad las 'verdades eternas' que se aplicarán a la creación, es decir, que las leyes de la naturaleza no le son impuestas desde fuera por una necesidad intelectual que obliga a su voluntad. Sin embargo, una vez creadas las leyes, Dios no puede alterarlas dado que Descartes subraya una y otra vez la inmutabilidad divina: Dios crea y conserva al mismo tiempo, de modo que el orden de la naturaleza se mantiene necesariamente" (2015, pp. 77-78). En este sentido, la posición de Descartes dentro de esta clasificación resulta bastante difícil: ni voluntarismo radical, ni intelectualismo radical.

9 Henry apunta a que fue una secularización de la teologia en el siglo xvII la que produjo un viraje importante hacia la concepción moderna de ley, donde esta es concebida como una "proposición precisa y específica que codifica regularidades observadas en la naturaleza pero que denotan una conexión causal subyacente" (Manzo, 2015, p. 82). En este sentido, la ley es una regularidad con un valor explicativo. 
creadas. Sin embargo, para muchos teólogos de la Edad Media estas proposiciones, derivadas de la filosofía aristotélica, negaban la omnipotencia de Dios. Desde este punto de vista, Dios no podía cambiar el mundo que había creado, entre otras cosas, porque sería ilógico crear para después destruir a placer. Esto implicaba que Dios "no estaba totalmente en control de sus propias acciones, porque siempre tenía que seguir los dictados de la razón y, por lo tanto, actuaba por necesidad" (Henry, 2009, p. 80). Es decir, el intelectualismo minaba la libertad divina y su poder, mientras el voluntarismo convertía al mundo en algo meramente contingente. Estas posturas partían de la discusión sobre la primacía de la voluntad sobre el intelecto o del intelecto sobre la voluntad; discusión afincada, así, sobre un problema en torno a las facultades divinas. Sostiene Henry:

en la historiografía de la ciencia estas dos teologías se han relacionado, especialmente en el período moderno temprano, a diferentes enfoques para la epistemología y metodología de la ciencia. El énfasis en la razón intelectualista de Dios va de la mano con filosofías naturales racionalistas. Puesto que Dios siguió los dictados de la razón en la creación del mundo, podemos reconstruir, por así decirlo, los procesos de pensamiento de Dios, y llegar en un proceso racional a una comprensión del mundo. Por el contrario, el énfasis voluntarista en la libertad de la operación de Dios se asocia con la creencia en la contingencia radical del mundo natural y la creencia concomitante que sólo podemos entender la creación de Dios a posteriori mediante el examen y sacar conclusiones empíricamente. (2009, p. 81)

Este es un punto importante de llegada, porque, dependiendo de las dos posturas, se ha intentado explicar el empirismo y el racionalismo en el nacimiento de la ciencia moderna. Las consecuencias epistemológicas, para decirlo en términos generales, son claras: el intelectualismo deriva en la matematización de la naturaleza y sus certezas, mientras el voluntarismo desemboca en el empirismo y sus probabilidades. En cuanto al problema del origen del "concepto de ley natural", el debate se ha desplazado a si Dios puede cambiar la legalidad del mundo (voluntarismo) o si debe ceñirse estrictamente a conservar lo creado, como pensaba Descartes y el intelectualismo.

La pregunta que surge, entonces, es ¿cómo ubicar a Francis Bacon dentro de esta discusión? Para dar una respuesta, es necesario volver a lo indicado atrás: "la ley suprema de la naturaleza”. 
En la fábula de "Pan o la naturaleza" de La sabiduría de los antiguos de 1609, presente también en De Augmentis de 1623, Bacon dice: "Pan [...] representa y exhibe la totalidad de las cosas o la naturaleza", y "tuvo su origen en el verbo divino a través de la materia confundida (ella misma creada por Dios)” (sDA, pp. 30 y 31 ). De aquí se resalta que Dios creó la materia, por lo tanto él es "la causa primera"; mientras que en la naturaleza, que es la "totalidad de las cosas", operan "las causas segundas" (Véase, AS., p. 22). En un principio la materia estaba desordenada en el caos, posteriormente Dios le dio orden al mundo e hizo el cosmos, por eso Dios es "creador e introductor de las Formas" (No., II, 15). La primera Forma que Dios creó fue la luz y luego las demás. El mundo es también una "cadena de las causas naturales" (sDA, p. 31) y es como una pirámide, por eso afirma Lord Verulam:

La totalidad de la naturaleza de las cosas es como una pirámide. Pues los individuos son infinitos y se reúnen en especies que son ellas mismas múltiples; a su vez, las especies se elevan hacia los géneros, y estos también se contraen al ascender hacia lo más general, de manera que entonces la naturaleza parece unirse como en un vértice [...] ya que las cimas de la naturaleza, es decir, las ideas universales, también en cierta manera llegan hasta lo divino. En efecto, el paso de la metafísica a la teología natural está preparado y próximo. (sDA, p. 32)

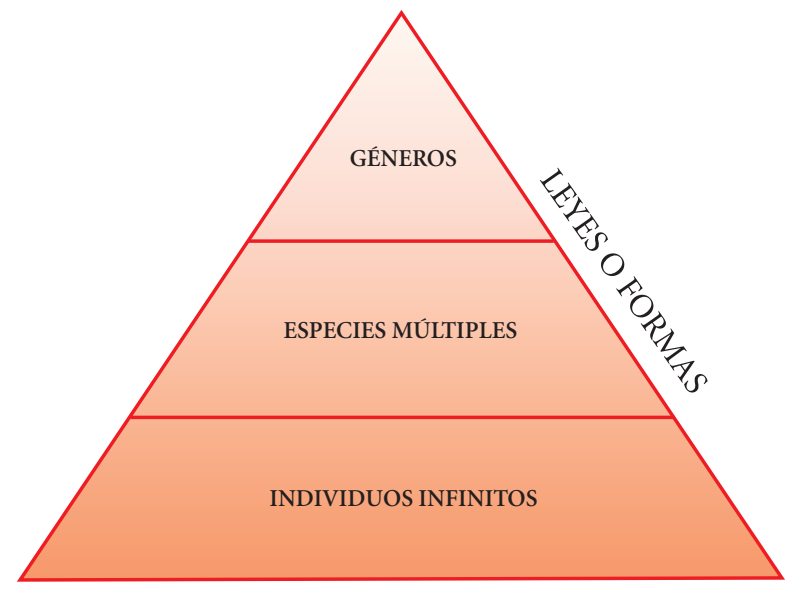

Figura 1. La pirámide de la naturaleza atravesada por las Formas o Leyes naturales ${ }^{10}$

10 La pirámide permite ver claramente por qué las Formas de Bacon no tienen nada que ver con las Formas aristotélicas, pues mientras las primeras atraviesan o cruzan la naturaleza en su conjunto, las de Aristóteles son formas de las "sustancias primeras" o individuos. 
El párrafo citado pone de presente el eclecticismo de Bacon. Aquí se adoptan los predicables de Aristóteles, se aceptan los conceptos de especie (dado por la Forma) y el de género, pero se alude de manera platónica a "ideas universales". Sin embargo, esta expresión "ideas universales" puede hacer alusión a las leyes universales de la naturaleza. Así mismo, la alusión a la pirámide y a la unidad invoca cierto neoplatonismo, debido, tal vez, a la influencia que tuvieron los escritos neoplatónicos de Ficino que circularon por Europa a partir del siglo xv. Sin embargo, no hay evidencia, como en muchos otros casos, de su presencia en la obra de Bacon ${ }^{11}$. Nos quedan textos como este, donde Bacon llama "ideas universales" a la cima de la naturaleza. Aquí también es de resaltar la relación entre metafísica y teología, no solo porque mantiene la distinción donde la metafísica es parte de la ciencia natural, sino porque el conocimiento de la estructura del mundo nos acerca más a Dios, no porque el conocimiento desentrañe sus misterios, sino porque nos persuade más de su existencia y omnipotencia.

La pirámide, por otro lado, explica el hecho de que Bacon acoja lo que la "Historia de las ideas" del siglo xx, en la versión de Arthur O. Lovejoy, llamó "la gran cadena el ser" (1936). Dice Bacon: "el hombre tiene algo de animal, el animal tiene algo de planta, la planta tiene algo de cuerpo inanimado, y todas las cosas son en verdad biformes y se componen de una especie inferior y de otra superior" (SDA, p. 33).

Lo importante de la pirámide es que está atravesada por la "cadena de leyes causales", sus jerarquías y sus gradaciones en escala ascendente.

Por eso, lo que Bacon llama "la ley suma" es la obra creada por Dios mismo, la naturaleza, su orden y su jerarquía. Esta proviene del verbo divino, del cual depende su inteligibilidad. En su temprano texto A Confession of Faith alude a que "Dios creó el cielo y la tierra y toda la multitud de generaciones, y les dio leyes constantes y eternas, las cuales nosotros llamamos naturaleza" (W., XIV, p. 49). De tal manera que esta expresión se repite en El avance del saber de 1605, La gran restauración de 1620 y De Augmentis de 1623. Ahora, esas leyes universales y eternas no excluyen los milagros. En New Atlantis hay un párrafo muy interesante que dice: "las leyes de la naturaleza son tus propias leyes y tú no las infringes sino por algún motivo poderoso"

11 Como ha mostrado Jardine (1974), la biblioteca de Bacon fue repartida entre sus acreedores, razón por la cual no hay seguridad sobre los autores que efectivamente leyó. Esto hace difícil la reconstrucción de las fuentes que usó. 
(2013, pp. 150-151, resaltados fuera del texto). Sin duda, Bacon creía que el hombre, en sus limitadas posibilidades, podía discernir "entre milagros divinos, obras de la naturaleza, obras humanas y engaños e ilusiones de toda especie" (NA., 2013, p. 150)12. Esto supone, entonces, que la regularidad natural (leyes) que Dios introdujo en la naturaleza no ata el poder divino ${ }^{13}$. En este sentido, la posición de Bacon es ambigua y no resulta fácil ubicarlo dentro del voluntarismo o el intelectualismo. Veamos.

Si se inscribe al Canciller dentro del voluntarismo se lo podría vincular equivocadamente con la totalidad de las doctrinas del nominalismo radical de Guillermo de Ockham. Si bien es cierto que el famoso principio: "debe saberse que todo lo que es, es singular y todo lo universal es singular" (Ockham, 1985, p. 58), el cual se deriva de la inexistencia de esencias o arquetipos (Gilson, 2007, pp. 626-627) en Dios ${ }^{14}$, llevó a la sustitución de la metafísica de lo universal por una metafísica de lo singular, a la tesis del conocimiento intuitivo y del concepto como signo natural ${ }^{15}$, y no como imagen, y a la correlativa experimentación del mundo contingente, su pensamiento no encaja exactamente con el pensamiento de Bacon. Si Ockham negó la realidad de los universales ante re $e$ in re, y la existencia de Ideas divinas que limitaran la omnipotencia de Dios, Bacon habló explícitamente de esas ideas ${ }^{16}$. En NO., I, 23 dice:

12 Sobre el tema de los milagros véase Weinberger, J. (2002, pp. 106-128).

13 Hay otro aspecto que puede verse como una excepción a la regularidad natural. Cuando Bacon habla de la historia natural alude a uno de los estados en que se encuentra la naturaleza, cuando esta es apartada de su estado habitual por las perversidades o insubordinaciones de la materia. En este caso, la materia se "sale" de su curso habitual y puede producir monstruos o deformaciones. De ahí que Bacon proponga una "Historia de las desviaciones" o una "Historia de las generaciones irregulares". Este postulado es conforme a las consecuencias que Bacon le atribuye a la caída que produjo el desequilibrio de la naturaleza misma.

14 Al respecto dice Gilson: "Precisamente porque no hay ideas en Dios, no hay universal en las cosas" (2007, p. 626).

15 La universalidad del signo consiste en su capacidad de reenvío a muchos singulares: "Los signos al mismo tiempo que son singulares, son universales, singulares en su ser, universales por el significado, esto es, son aquellos que son signos de muchos [...] El ser universal no compete sino a los signos" (0ckham, 1985, pp. 58-59). Como ha dicho Daniel Herrera Restrepo: "Lo que significa que la universalidad es una cuantificación lógica, extrínseca al signo mismo [...] No hay similitud entre signo y realidad. Ella es táctica. Ella se da entre individuos reales". Por eso el concepto es un signo vacio, meramente denotativo (2009, pp. 74-75).

16 El problema es que Bacon no cita a Okham nunca. Y, de hecho, los estudios aparecidos en The Cambridge Companion to Francis Bacon no establecen una relación explicita entre los dos autores. 
No es poca la diferencia existente entre los ídolos de la mente humana y las ideas de la mente divina, es decir, entre algunas opiniones vacías y los verdaderos signos e improntas marcadas en las criaturas tales como se les puede descubrir. (Cursivas fuera del texto)

Esas ideas de la mente divina (No., I, 124) son los sellos que el Creador imprimió en las criaturas, los cuales pueden alcanzarse una vez eliminados (en la medida de lo posible) los ídolos, son prueba de que su pensamiento no seguía en este punto a Ockham, sino más bien a Santo Tomás. En la Suma teológica (cuestión 44, art. 3) sostiene el Aquinate:

es preciso reconocer que en la divina sabiduría están las razones de todas las cosas y a las que hemos llamado ideas (c.15, a.1) esto es, formas ejemplares existentes en la mente divina. Estas formas, aunque se consideren múltiples con respecto de los seres, no son en realidad otra cosa que la esencia divina. (1985, p. 65, resaltados fuera del texto)

Pero sobre este tema surge otro problema. Porque Bacon habla de un Dios creador de las Formas (No., II, 15). En este caso, Dios sería fuente de estas, con lo que el acercamiento parecería ser más a Duns Scoto. Aquí de nuevo el problema para la lectura es el eclecticismo baconiano.

Por otra parte, si bien el concepto de ley natural de Bacon alude a leyes divinas constantes y eternas, estas pueden ser variadas por Dios, a su voluntad, con lo cual hay de nuevo un acercamiento a las tesis nominalistas. Cabría hablar, posiblemente, de un pseudo-ockhamismo en Bacon, el cual no puede documentarse en sus obras, y no pasa de ser, más bien, una suposición que encuentra algún sustento en la fuerte influencia del nominalismo en el empirismo inglés.

Por lo demás, como afirma Pérez-Ramos, "Bacon, a diferencia de Descartes en Principia Philosophie, no esboza ninguna conclusión acerca de las leyes de la naturaleza argumentando desde sus pretendidos atributos" (1988, p. 126). Pero tampoco su posición puede ser confundida con el aristotelismo o el escolasticismo: "obedecer la naturaleza para conquistarla o dominarla apenas encaja con la concepción aristotélica de la investigación natural como una forma privilegiada de conocimiento contemplativo" (1988, p. 128). Esta lectura de Bacon —no renacentista totalmente 
ni equiparable a la de Descartes o Newton - debe poner de presente que sus "leyes de la naturaleza" no son matematizaciones de la naturaleza como en Galileo, si bien Bacon dio importancia a la matemática en la física, donde los alcances eran limitados e, igualmente, pensó que cierta cuantificación de la materia debía ser importante en la investigación:

en toda investigación de la naturaleza, deberá observarse la cantidad de cuerpo que se requiere para la producción de un efecto determinado, esto es, la dosis del mismo, procediendo con cautela ante el demasiado y el poco. (No, II, 47)

Hay que resaltar que la Forma baconiana es una perspectiva de la naturaleza diferente a sus contemporáneas. En la unidad de materia y movimiento de la Forma están los “últimos elementos del cambio". Pérez-Ramos recuerda que la llamada "Revolución cientifica" más que de la imposición de una nueva metodología, requirió de un cambio en "la subyacente teoría de la materia en orden a hacer posibles modos alternativos de investigación física” (1988, p. 97). Y en esto tiene razón, dada la variedad de propuestas y discusiones que se dieron en el siglo XVII, por ejemplo, en torno a la matematización de la naturaleza y los límites mismos del mecanicismo, así como en torno a las cualidades (Schapin, 2000, pp. 69 y ss.).

Por eso el aforismo 3, de No., II es fundamental para comprender el papel que Bacon da a las Formas y lo que quiere decir con ellas:

Quien conoce las Formas abraza la unidad de la naturaleza en materia disparísimas y, por tanto, puede descubrir y producir lo que hasta ahora no se ha efectuado, cosas que ni las vicisitudes de la naturaleza, ni las actividades experimentales, ni el azar han producido jamás o sometido nunca a la consideración humana”. (Resaltados fuera del texto)

El descubrimiento de las Formas lleva a desentrañar el misterio del gran esquematismo o mundo, posibilitando que la ciencia sea una especie de espejo de la realidad natural. Como dice Kuno Fischer: "la ciencia es el edificio del mundo en la mente humana” (Fischer, 1857, p. 67). Por eso la Forma aparece como ley, regularidad, que rige todo lo que sucede en el mundo natural, sus fenómenos: 
cuando yo hablo de Formas no entiendo otra cosa que las leyes y determinaciones de absoluta actualidad, las cuales gobiernan y constituyen cualquier naturaleza simple, como el calor, la luz, el peso, y ello en todo tipo de materia y sujeto susceptible. Así, pues, la Forma del calor o la Forma de la Luz y la Ley del calor y la ley de la luz son la misma cosa y nunca nos alejamos o retiramos de las cosas mismas y de la parte operativa. (W., VIII, p. 206 [T]; NO, II, 17)

La Naturaleza es, pues, gobernada por leyes, de ahí que ese gobierno sea desentrañable a partir del descubrimiento experimental de las Formas. Estas tejen la red de relaciones en el mundo natural mismo. Por eso, la Forma establece relaciones entre las naturalezas simples. En un cuerpo blando, por ejemplo, debe existir una tensión equilibrada entre lo denso y lo raro, razón por la cual el cuerpo no es totalmente compacto y sólido, pero tampoco totalmente tenue. El reto es, pues, desentrañar las relaciones entre las cualidades y su mezcla, así como los distintos cambios en la naturaleza. Con todo, creo que Bacon hizo un esfuerzo por crear una ontología natural materialista que permite explicar (con sus deficiencias como cualquier otro sistema de pensamiento) el mundo natural y con el cual dio respuesta a las discusiones de su época.

\section{La Forma y la ley jurídica}

Antes de intentar sistematizar el concepto de ley natural en Bacon, es necesario aludir a la relación que esta noción tiene con la ley jurídica. Este tema es imprescindible dada la formación jurídica de Bacon y a la influencia del derecho romano en la legislación moderna, especialmente, en la organización de las nacientes monarquías absolutistas como la inglesa. Al respecto, Silvia Manzo ha dicho que "al parecer” hubo vinculación entre sus nociones de ley jurídica y ley natural (2015, p. 84). Julian Martin, por su parte, ha dedicado un capítulo completo de su libro Francis Bacon, the State, and the Reform of Natural Philosophy al tema de la ley en el Canciller, mostrando los procedimientos jurídicos de la época y la manera como estos se relacionan con el método baconiano. Dice Martin: "Los procedimientos de Bacon en filosofía natural fueron adaptados por él de la ley inglesa. Específicamente ciertos procedimientos en la investigación legal y juicios judiciales” (2007, p. 72). Estos procedimientos son, por ejemplo, el establecimiento de los hechos mediante testimonios, el registro minucioso de esos testimonios, la determinación de la dificultad a investigar mediante 
nuevas pesquisas, el uso de la "tortura judicial", el valor de la credibilidad dada a los testigos según su posición social y procedencia, las instancias, la comparecencia, el juez como intérprete de la ley, el uso de la analogía con las causas anteriores, etc. De tal manera que estos procedimientos tienen su correlato en la colección de las historias naturales, su registro, la determinación del problema a investigar, el experimento mismo concebido como vejación o tortura a la naturaleza, el empleo de testigos en los experimentos, la comparecencia en las tablas, el papel del intérprete de la naturaleza, entre otras similitudes. La conclusión de Martin es que "el libro II del Novum Organum, entonces, describe la labor de un juez" (2007, p. 168). Martin basa su analogía general de los procedimientos en la jurisprudencia con los de la filosofía natural de Bacon, aludiendo a la unidad del conocimiento que expuso el Canciller, y en que la filosofía natural reformada es la base de una sociedad ordenada. Con todo, la conclusión es exagerada y, a mi juicio, muy pocos de estos elementos apuntan a determinar si fue la noción de ley de la jurisprudencia la que influyó en la elaboración del concepto de ley natural, o si fue a la inversa.

Bacon habló, en efecto, de analogías con "procesos civiles", hizo alusión a los testigos y los interrogatorios, al registro de la información, los parágrafos o artículos de la ley, las instancias, la comparecencia, etc., (DGI., PP. 25-26; NO., II, 2, 13; W., VIII, pp. 351 ss.), pero estos elementos no nos dicen mucho de la relación que buscamos. La relación se puede encontrar en textos como "The case of the Post-nati of Scotland"17 o "Maxims of Law". En este último escrito, probablemente de 1597, el Canciller alude a lo que hoy podemos llamar la racionalización del sistema jurídico, esto es, la reducción de las leyes en aras de hacerlas más eficientes y perfectas, tal como en su momento hizo el emperador Justiniano, quien "las redujo de infinitos volúmenes [...] a un competente y uniforme cuerpo legal" (W., XIV, p. 172). En este texto el rey es considerado el "alma de la ley" (W., XIV, p. 171), lo cual se aviene bien con las prerrogativas de las monarquías absolutistas, las cuales, entre otras cosas, tuvieron que unificar los sistemas jurídicos para poder ejercer una soberanía sobre la totalidad de la población y sus asuntos (Heller, 2014, pp. 176-178).

Lo interesante de este texto es que alude a la simplificación de la pluralidad de la ley, lo que implica que esta debe ser plenamente reducida a unos pocos principios generales. ¿Cómo se obtienen esos principios generales? Aquí es necesario aludir

17 Este caso gira en torno a si se debe naturalizar o no en Inglaterra un niño nacido en Escocia, reinos unidos en la época "bajo una ley y un parlamento". Es probablemente de 1608 (W., XV, p. 195). 
a la tradición inglesa del Common Law. En este sistema existen leyes basadas en la costumbre, en la tradición, que sirven como modelo para resolver los futuros litigios. Estas son "leyes fundamentales y comunes", que en el nacimiento de los Estados absolutistas reemplazaron una gran variedad de normas locales, municipales. Estos principios comunes son inferidos de los precedentes judiciales. En este sentido, se puede decir, las leyes comunes y fundamentales equivalen a los "axiomas" que se obtienen por inducción del material empírico (Cf., Martin, 2007, p. 95). Por eso la ley jurídica así concebida tiene carácter general y gobierna y rige los actos humanos. Esta es la manera como se constituyó el sistema jurídico inglés: a partir de muchos casos comunes, de precedentes, se obtiene la ratio decidendi, esto es, la razón de la decisión que puede ser aplicada posteriormente a un caso concreto. En este sentido, la ley es prescriptiva y predictiva. De ahí que el derecho anglosajón sea estable y funcione con unos pocos principios, todos extraídos de la experiencia. Ahora, ¿qué quiso decir Bacon cuando dijo: "la ley común es más valiosa que la ley estatuida [positiva], sin embargo, la ley de la naturaleza es más valiosa que ambas"? (W., XV, p. 202). A mi parecer, que si bien la ley es un acto de la voluntad, este acto debe atender a la ley natural (Law of Nature) o Forma descubierta experimentalmente, la cual, como ya se dijo, fue impresa por Dios en la naturaleza misma. De tal manera que son las leyes de la naturaleza las que determinan la legislación civil del reino, lo cual es claro en la subordinación que hace Bacon de la ley positiva y en el postulado según el cual el progreso de la ciencia determina el orden político, su estabilidad. Esta concepción de la ley, limitada por la ley natural, no choca con el poder absoluto del rey, pues de acuerdo a la tradición inglesa, el poder del rey cada vez era más limitado por el parlamento, tal como era costumbre desde la Carta Magna de 1215. Con todo, no hay que olvidar que fue justamente Jacobo I quien subvirtió esa tradición, hecho que lo llevó a cerrar el parlamento y que traería consecuencias desastrosas para las siguientes décadas en Inglaterra.

Dice Friedrich Steinle: "Bacon fue uno de los pocos que dibujó una analogía explícita entre filosofía natural y temas de legislación” (2008, p. 216). Esto es innegable, ya lo vimos también con Julian Martin. Sin embargo, a mi parecer, es su concepto de ley jurídica el que está subordinado al de ley natural, lo que no puede llevar a desconocer que, como abogado y político, traspasó algunos procedimientos judiciales y los incorporó en el método inductivo. 
Finalmente, hay que decir que así como las leyes jurídicas prescriben comportamientos humanos, ordenan; algunas describen procedimientos, términos, etc., la ley natural tiene también una función prescriptiva de los fenómenos físicos o naturales. En esta analogía podemos encontrar su aproximación.

\section{La ley del movimiento y la parte operativa ${ }^{18}$}

La Forma también es "la ley del acto o movimiento" (NO., I, 51). La ciencia natural estudia estos movimientos en "naturalezas dispares", acorde con el universo. En No, II, 48 Bacon nos dice: "Los movimientos de los cuerpos se componen, descomponen y complican en una medida no menor que los cuerpos mismos". En este sentido, el movimiento de resistencia busca que la materia no sea aniquilada completamente ${ }^{19}$, pues "jamás podrá ocurrir que la materia se aniquile o no esté en algún sitio". El movimiento de conexión, por su parte, se refiere a que "los cuerpos no toleran ser alejados del contacto con otro cuerpo por amar la conexión y contacto mutuo". En este caso, se deduce, se trata de cuerpos simpáticos que buscan el consenso en su organización. El movimiento simple de libertad, a su vez, explica que los "cuerpos traten de liberarse de una presión o tensión contranatural y buscan volver a las dimensiones apropiadas a su cuerpo". Por ejemplo, "el agua se libera de una presión fluyendo; el aire volando". De los movimientos que Bacon expone en NO, II, 48, se resalta el predominio de unos sobre otros, las resistencias, las composiciones, desagregación, la manera como unos asimilan a otros, etc.

En general, en Bacon el movimiento depende de los apetitos de la materia y de la tensión entre la materia tangible y la pneumática. No se explica, pues, por la Forma aristotélica. La materia tangible es densa, dura, pesada, mientras la pneumática carece de peso, es rara, invisible; es más tenue y tiene gran movilidad. Lo pneumático alude a una vieja tradición relacionada con un "soplo", un "viento", un "ánimo" pero, ante todo, es material y activo (Véase Rusu, 2013, p. 52; Manzo, 2006, pp. 32-43). Ahora, la materia pneumática se divide en tres: pura, ligada (Spiritus) e imperfecta. De estas tres, el papel fundamental para el estudio del movimiento lo desempeñan los espíritus. "El espíritu no es otra cosa que un cuerpo natural rarificado e inserto

18 Sobre el movimiento en Bacon, véase Manzo (2004).

19 Bacon sostiene que tal movimiento era el que los escolásticos definían bajo el principio de "Dos cuerpos no pueden estar en el mismo lugar". 
en las partes tangibles, que son como su envoltorio" (Manzo, 2006, p. 37). Por eso dice Bacon: "Todo lo tangible a nuestro alrededor contiene un espíritu invisible e intangible, al cual esconde como bajo un vestido" (NO., II, 40); es un cuerpo que ocupa un lugar, tiene dimensión, y es real. Todo cuerpo tangible posee dentro de sí espíritus que tienen tendencias o apetitos y gracias a ellos se produce el movimiento. Un ejemplo que nos permite explicar la desecación (como en las uvas pasas) y el ablandamiento es el siguiente: "el espíritu de una cosa tangible, cuando es emitido al exterior, contrae y deseca los cuerpos; si se mantiene en el interior, el cuerpo se enternece y ablanda" (NO., II, 40).

Son todos estos actos los que caen bajo la ley o la Forma. La ley del movimiento describe esas operaciones y funcionamientos. Aquí es necesario incluir la plegabilidad de la materia, su flexibilidad, la cual permite explicar movimientos como los de la contracción o expansión, prescindiendo del vacío atómico. Es posible ver la plegabilidad y flexibilidad como "actos" o movimiento, con lo cual la sustitución que hizo Bacon en 1620 de la teoría atómica por la materia plegable (NO., II, 48) implica también que ahora la Forma — no compatible con el atomismo- cobija y debe codificar esos pliegues y repliegues.

¿Cómo se relaciona lo anterior con la parte operativa? No olvidemos que en Bacon la metafísica tiene dos partes: una teórica, que estudia la causa formal o Formas; otra práctica, constituida por lo que él llama, siguiendo la tradición renacentista de Ficino, Agripa, Giorgi, etc., como "magia natural" o también "ciencia activa”. Pues bien, en el Canciller hay una unidad entre ambas partes. Esto es claro en NO., II, 3 cuando dice:

Quien conoce las Formas abraza la unidad de la naturaleza en materia disparísimas y, por tanto, puede descubrir y producir lo que hasta ahora no se ha efectuado, cosas que ni las vicisitudes de la naturaleza, ni las actividades experimentales, ni el azar han producido jamás.

Esta unidad entre la parte teórica y la parte práctica es la que explica el famoso lema "Knowledge is power" - saber es poder-, pues si se alcanza la Forma o ley, es decir, si se conoce la naturaleza en materias dispares, es posible producir el efecto deseado. Es esto lo que explica la importancia de la parte operativa en Bacon - y su distanciamiento del aristotelismo y la escolástica-, pues con ella no solo se garantiza la verdad, sino que también es posible a) la reproducción de naturalezas simples, b) la 
creación de cualidades nuevas, c) el trasplante de las Formas, d) la convertibilidad de un cuerpo en otro, e) la creación de obras y artefactos que mejoren la vida humana. Las operaciones son, pues, "prendas de verdad" (No, I, 74) ${ }^{20}$, lo cual implica entrever una relación entre verdad y utilidad, sin caer en el utilitarismo vulgar, pues "al hablar de utilidad y la acción - dice Lord Verulam - no me refiero a ese fin antes mencionado de aplicar el conocimiento al lucro y provecho profesional" (AS., p. 50). Esta relación entre utilidad y verdad es necesaria porque "tan sólo un método verdadero puede dar lugar a obras reales” (Rossi, 1966, p. 146).

Solo con la magia natural o con la ciencia activa, como lo bosquejó Bacon en La gran restauración, puede el hombre ejercer el imperio humano sobre el universo. Para ello, debe obedecer (atender) a las leyes de la naturaleza. La clave de este imperio sobre el mundo natural es:

[E]l único poder que sobre la naturaleza tiene el hombre es el del movimiento - esto es, reunir o separar los cuerpos naturales [...] - allí donde es posible mover en uno $\mathrm{u}$ otro sentido los cuerpos naturales, el hombre y el arte pueden hacerlo todo, si tal posibilidad no les es dada, nada pueden hacer. (W., X, p. 408. Supresiones y cursivas fuera del texto)

La llave de la naturaleza es claramente la intervención del movimiento y la manipulación de las configuraciones materiales. Esta es la puerta de entrada al gran reservorio natural, cuyo agenciamiento llevará el poder del hombre más allá de lo habitual, posibilitando el dominio deseado. El control del movimiento, de los procesos latentes o movimientos continuos, los pliegues y repliegues de la materia flexible, etc., facilitan la operación sobre el cuerpo natural. Sin esto, no es posible transmutación alguna de los cuerpos, así como otro conjunto de obras derivadas del progreso científico y del acrecentamiento del saber. Solo con el arte, que Bacon no diferencia de la naturaleza más que en la causa eficiente, puede el hombre realizar los más prometeicos proyectos. Bacon lo expuso con toda claridad cuando postuló en 1624 que la ciencia debía buscar:

La prolongación de la vida, la restitución de la juventud en algún grado, la curación de las enfermedades consideradas incurables, [...] la alteración de la complexión, de la gordura y la delgadez; la modificación de la estatura,

20 "Sólo a través de las consecuencias prácticas puede la verdad de una explicación o postulado científico ser verificada” (Jardine, 1974, p. 115). 
la modificación de las características físicas [...], la creación de especies nuevas, el trasplante de una especie dentro de otra especie, la creación de instrumentos de destrucción, así como de guerra y venenos; la aceleración del tiempo de maduración [...]; aceleración del tiempo de la germinación. (W., V., pp. 415-416. Supresiones y cursivas fuera del texto)

Estos proyectos muestran la magnitud del imperio humano sobre el universo en Bacon. Los límites de ese imperio sobre la naturaleza están dados por: a) la naturaleza misma de la materia y b) la acumulación y el progreso del saber científico y tecnológico.

Es aquí cuando se hace patente por qué la Forma no es una receta como en PérezRamos o Lisa Jardine.

Para Jardine, la Forma ofrece "una receta para producir la propiedad especificada [la naturaleza simple] en cualquier clase de materia" con aras a la transmutación de los cuerpos (1974, p. 111). Mientras que en Pérez-Ramos lo que Bacon llama 'Form' busca la esencia de un fenómeno re-describiéndola en una "receta para la operación exitosa sobre la base de la eficiencia pragmática" (1996a, p. 109; igualmente, Cf. 1988, p. 131). En ambos casos, la "receta" parece apuntar a una fórmula infalible que garantiza la operación, sin embargo, esa palabra es equívoca. Una receta no solo ofrece los ingredientes para hacer algo, sino también la manera como ese algo se debe hacer. Por lo demás, tener los ingredientes es solo un paso que no garantiza el éxito de la operación.

Que la Forma no es una receta se comprende si se atiende a algunas tempranas advertencias de Bacon en su texto de 1607 Delineatio o Descripción y sumario de la segunda parte de la Instauratio donde dice:

la operación humana se ve forzada a sufrir estrecheces mucho mayores que la ciencia, debido a las múltiples indigencias y carencias del individuo, hasta tal punto que para la operación se requiere con más frecuencia, no tanto la sabiduría completa y libre acerca de lo que puede ser hecho, cuanto la prudencia sagaz para elegir entre lo que está a la mano. (Dss., p. 45. Resaltados fuera del texto) 
Esto indica que la parte operativa es, de hecho, más difícil y más compleja que la teórica porque implica utilizar mediaciones ("lo que está a la mano"). Por lo demás, en este libro Bacon señala que en la parte operativa se maniobra con la deducción, con lo cual se apunta de un modo "más oscuro e incierto hacia lo particular y hacia las obras”. Aquí opera una escala descendente:
pues toda operación se mueve entre individuos, los cuales se hallan en el lugar más bajo [...] no se puede llegar a ellos mediante axiomas simples, puesto que toda obra, así como el procedimiento para llevarla a cabo, se emprende y se traza partiendo de la confluencia de diversos axiomas. (DSs, p. 53. Supresiones fuera del texto)

Aquí la investigación no tiene por objeto una causa o axioma, sino la "ejecución de alguna obra". Lo que Bacon quiere decir, entonces, es que las operaciones requieren otras mediaciones para las cuales los axiomas generales no tienen gran utilidad. Por eso deben ser axiomas medios. Por ejemplo, del axioma físico "El calor dilata los cuerpos" no puedo pasar directamente a una operación u obra. Se necesitan otros axiomas u otras especificaciones, tales como saber el tipo de elemento sobre el que se trabaja, si es metálico o de otra naturaleza y cómo y con qué medios lograr la dicha dilatación. De la ley de la gravedad tampoco puedo deducir directamente cómo crear un cohete para salir de la tierra, se necesitan otros descubrimientos.

Para Bacon la ejecución de una obra implica, también, "confeccionar tablas prácticas generales por medio de las cuales se tracen con mayor facilidad y prontitud toda clase de diseños y obras" (Dss, p. 55). Por eso, en la parte operativa se va de "experimento en experimento", y no de axioma en axioma, para buscar un resultado. Este método por eso "abre una cierta vía de obtención, insegura y resbaladiza, aunque no por ello se ha de abandonar del todo en el silencio" (Dss, p. 55). Por lo anterior, sostengo que la expresión "receta" es inadecuada, pues omite todo este conjunto de problemas. Por lo demás, Bacon había planificado escribir una parte titulada "Deducción a la praxis" (NO, II, 21) que nunca vio la luz. Esta ayuda a la razón permitiría arrojar claridad sobre la parte operativa. 


\section{Conclusión}

Por lo expuesto, es posible afirmar lo siguiente: en Francis Bacon la naturaleza está regida por Formas o leyes introducidas por Dios. El descubrimiento de estas Formas es el objetivo de la ciencia. Específicamente, la ley es producto de una generalización empírica, no matematizada, y alude a una regularidad observable en la naturaleza, que puede ser conocida utilizando correctamente el método inductivo. Estas leyes son eternas, universales, constantes y uniformes. Al ser un conocimiento de las causas, tienen un valor explicativo; y al ser norma para la reproducción de las naturalezas simples, así como para la creación (mediada) de obras, tienen un valor predictivo. En Bacon la Forma como ley alude, pues, a la unidad de materia y movimiento. Por eso los sentidos "diferencia verdadera", "fuente de emanación”, etc., no dan razón de estos aspectos. De igual forma, según se desprende del análisis hecho, la ley jurídica está determinada por la ley natural, si bien Bacon extrapoló procedimientos jurídicos al método inductivo.

La Forma también tiene que ver con la ley de la configuración de las naturalezas simples y de la regularidad de los apetitos, deseos, pliegues y repliegues de la materia, si bien este punto merece una mayor investigación y elucidación.

La respuesta de Bacon al problema de la materia y el movimiento fue una de las múltiples opciones que contribuyeron a la configuración de la llamada Revolución científica del siglo XVII, razón por la cual el pensamiento de Bacon no puede desecharse como meramente renacentista, obviando que el Canciller puso en la escena nuevamente el problema de la inducción, se convirtió en vocero de la filosofía experimental, valoró altamente las artes mecánicas, abogó por la institucionalización de la ciencia, fomentó la creación de las enciclopedias y, por último, dio gran impulso a la confección de las historias naturales. Estos aspectos son decisivos en la configuración de la ciencia moderna. 


\section{Referencias}

Aquino, T. (1985). Summa teológica. Selección. Madrid: Espasa-Calpe.

Bacon, F. (As). El avance del saber [1605]. Madrid: Alianza Editorial, 1988. (Introducción de Alberto Elena y Traducción y notas de María Luisa Balseiro).

Bacon, F. (DGI). Descripción del globo intelectual [1612]. Madrid: Tecnos, 1989. (Estudio

Preliminar, traducción y notas de Alberto Elena y María José Pascual).

Bacon, F. (Dss). Delineatio o Descripción y sumario de la segunda parte de la Instauratio [1607]. Madrid: Consejo Superior de Investigaciones científicas, 1985. (Edición bilingüe latín-español y traducción de J.M. Artola y M. F. Pérez).

Bacon, F. (NA). "La Nueva Atlántida” [1626]. (Traducción de Juan Adolfo Vásquez), Buenos Aires: Editorial Losada, S.A., 2013.

Bacon, F. (NO). Novum Organum [1620]. En La gran restauración (Traducción y Estudio Introductorio de Miguel A. Granada). Madrid: Tecnos, 2011.

Bacon, F. (SDA). La sabiduría de los antiguos [1609]. Madrid: Tecnos, 2014. (Estudio preliminar, traducción y notas de Silvia Manzo).

Bacon, F. (W). The Works of Francis Bacon (James Speeding, Robert Leslie Ellis y Duglas Denon Heath, Eds.), 1857-1874. Boston: Houghton, Mifflin and Company: The Riverside Press, Cambridge. En: http://onlinebooks.library.upenn.edu/webbin/ metabook?id=worksfbacon.

Del Canto, J. (2010). "Natura naturans y natura naturata en Spinoza y David Nieto, Haham de la comunidad sefardita de Londres a principios del siglo xvirI". Anales del seminario de historia de la filosofía, 27, 165-188.

Dickie, W. (2007). Form and Simple Nature in Bacon's Philosophy. Monist, 33, 428-437.

Ellis, R. "General Preface to Bacon's Philosophical Works". En The Works of Francis Bacon, J. Speeding, R. Leslie Ellis y D. Denon Heath (Eds.). Londres, 1857-1874.

Farrington, B. (1971). Francis Bacon: filósofo de la revolución industrial. Madrid: Editorial Ayuso. 
Fischer, K. (1857). Francis Bacon of Verulam. Realistic Philosophy and its Age (Traducido del alemán por Jhon Oxenford). Londres. Versión online en: https:// archive.org/stream/cu31924029010219\#page/n5/mode/2up.

Fletcher, A. (2005). "Francis Bacon's Forms and the Logic of Ramist Conversion". Journal of the History of Philosophy, 43(2), 157-169.

Gaukroger, S. (2001). Francis Bacon and the Transformation of Early Modern Philosophy. Cambridge: Cambridge University Press.

Gilson, É. (2007). La filosofía en la Edad Media. Desde los orígenes patrísticos hasta el fin del siglo xIv. Madrid: Gredos.

González, A. M. (Eds.) (2008). Contemporary Perspectives of Natural Law. Natural Law as a limiting Concept. Routledge.

Granada, M. (2000). El umbral de la modernidad. Estudios sobre filosofía, religión y ciencia entre Petrarca y Descartes. Barcelona: Herder.

Heller, H. (2014). Teoría del Estado. México: Fondo de Cultura Económica.

Henry, J. (2009). "Voluntarist theology at the origins of Modern Science: a response to Peter Harrison”. History of Science, 47, 79-113.

Herrera, D. (2009). “La concepción lingüística del conocimiento en Ockham”. En Por los senderos del filosofar (pp. 74-75). Bogotá: Universidad de San Buenaventura.

Jardine, L. (1974). Francis Bacon. Discovery and the Arts of Discourse. Cambridge: Cambrige University Press.

Kristeller. P. O., (2005). Ocho filósofos del Renacimiento italiano. México: Fondo de Cultura Económica.

Lovejoy, O. A. 1936). The Great Chain of Being. A study of the History of and Idea. Harvard University Press.

Manzo, s. (2004). "Francis Bacon y la concepción aristotélica del movimiento en los siglos xvi y xvII". Revista de filosofía, 29(1), 77-97.

Manzo, S. (2006). Entre el atomismo y la alquimia. La teoría de la materia de Francis Bacon. Buenos Aires: Editorial Biblos. 
Manzo, S. (2015). "Las leyes de la naturaleza y la ciencia en el siglo xviI", en: Melogno, P. (Comp.), Ciencia, matemática y experiencia. Estudios en Historia del pensamiento científico (pp. 72-78). Montevideo: índice Grupo Editorial.

Martin, J. (2007). Francis Bacon, the State, and the Reform of Natural Philosophy. Cambridge: Cambridge University Press.

Ockham, G. (1985). Principios de teología. Madrid: Sarpe.

Pérez-Ramos (1988). Francis Bacon's Idea of Science and Maker's Knowledge Tradition. London: Oxford University Press.

Pérez-Ramos, A. (1996). “Bacon's form and the maker's Knowledge Tradition”. En Peltonen, M. The Cambridge Companion to Francis Bacon (pp. 99-120). Cambridge, Cambridge University Press.

Rossi, P. (1966). Los filósofos y las máquinas. 1400-1700. Barcelona: Editorial Labor S.A. Rossi, P. (1990). Francis Bacon: de la magia a la ciencia. Madrid: Alianza Editorial.

Rusu, D. (2013). From Natural History to Natural Magic: Francis Bacon's Sylva Sylvarum. Bucarest: Radboud University Nijmegen.

Schapin, S. (2000). La revolución científica. Una interpretación alternativa. Barcelona: Paidós.

Steinle, F. (2008). "From Principles to Regularities: Tracing 'Las Nature' in Early Modern France and England". En Natural Law and Laws of Nature in Early Modern Europe. Jurisprudence, Theology, Moral and Natural Philosophy (pp. 216-231) (Lorraine Daston y Michael Stolleis, Eds.). Burlington, usA.

Urbach, P. (1987). Francis Bacon's Philosophy of Science. An account and a Reppraisal. La Salle, Illinois: Open Court.

Weeks, S. (2007). Francis Bacon's Science of Magic. The University of Leads, Department of Philosophy.

Weinberger, J. (2002). "On the miracles in Bacon's New Atlantis". En Francis Bacon's New Atlantis. New Interdisciplinary Essays (pp. 106-128). Manchester University Press. 
Yates, F. A. (2001). La filosofía oculta en la época isabelina. México: Fondo de Cultura Económica.

Zagorin, P. (1999). Francis Bacon. Princenton University Press.

Zilsel, E. (1942). "The genesis of the concept of Physical Law". Philosophical Review, 3, 245-279.

Zilsel, E. (2000). "The sociological roots of Science". Social Studies of Science, 30(6), 935-949. 